\title{
Saturación y vacío. La dicotomía del humano contemporáneo.
}

Saturation and vacuum. The dichotomy of the contemporary human.

\author{
Héctor Sevilla Godínez \\ Universidad de Guadalajara (MÉXICO) \\ CE: hectorsevilla@hotmail.com / ID ORCID: 0000-0002-1055-6059
}

DOI: $\underline{10.32870 / \text { sincronia.axxiv.n77.23a20 }}$

Esta obra está bajo una Licencia Creative Commons Atribución-NoComercial 4.0 Internacional

$\mathrm{BY} \cdot \mathrm{NC}$

Recibido: 05/08/2019

Revisado: $15 / 10 / 2019$

Aprobado: 02/11/2019

\section{RESUMEN}

La intención del presente artículo consiste en explicar las condiciones que provocan que la vivencia del vacío sea desaprovechada. Usualmente se teme al vacío, de modo que al intentar compensarlo se frena su función potencial de ser punto de partida para el desarrollo o el aprendizaje. En el texto se muestran cuatro maneras en las que la destemplanza es evidencia de una saturación compensatoria que provoca mayor destructividad: conductas de riesgo por excesos, distracciones o desatenciones, codependencias y apegos materiales. A la vez, los siguientes párrafos proporcionan concepciones que permiten significar de manera distinta las circunstancias implicadas en las vivencias descritas.

Palabras clave: Vacuidad. Compensación. Codependencia. Fetichismo. Aprendizaje.

\section{ABSTRACT}

The intention of this article is to explain the conditions that make the experience of emptiness wasted. There is usually a fear of emptiness, so trying to compensate for it reduces its potential function as a 
starting point for development or learning. The text shows four ways in which the imbalance shows a compensatory saturation that causes greater destructiveness: risk behaviors due to excesses, distractions or negligence, codependencies and material dependencies. At the same time, the following paragraphs provide concepts that allow different meanings of the circumstances involved in the described experiences.

Keywords: Emptiness. Compensation. Codependence. Fetishism. Learning.

\section{Introducción}

Distinta a la compensación, que busca disminuir la ansiedad debido a una carencia, la destemplanza supone un desequilibrio dañino que no aporta ningún beneficio explícito al individuo. La destemplanza se convierte en un peligro cuando el desequilibrio se vuelve recurrente, ordinario, habitual y constante. A pesar de que es conocida la sugerencia de que todo debe vivirse con medida, resultan evidentes las exageraciones en algunos ámbitos de la existencia cotidiana de muchos seres humanos.

Enseguida se abordarán cada una de las cuatro modalidades de la destemplanza: los excesos de orden corporal, los distractores específicos, el control interpersonal, la violencia y la exclusividad afectiva hacia los objetos.

\section{Excesos corporales}

Uno de los más graves problemas de salud en varios países es el abuso del cuerpo, es decir, el maltrato causado a partir de inadecuados hábitos o excesivas cargas químicas y alimenticias que son permitidas en el propio cuerpo. Probablemente uno de los excesos corporales más recurrentes, con repercusiones físicas notables, es el de la alimentación excesiva. Los excesos en el consumo de alimentos acarrean una serie de problemas de diversa índole como la hipertensión, la diabetes, los desequilibrios de colesterol, la artrosis, la fatiga, las dificultades respiratorias, los problemas de 
estima, los trastornos del sueño y varios más. Evidentemente, todos los anteriores se derivan de la obesidad, la cual deviene en problemas sociales e interpersonales.

Los problemas de la alimentación excesiva resultan altamente perjudiciales y variados. El exceso en el consumo de alimentos acontece usualmente cuando se está buscando desatender algún problema fundamental de fondo. Nuestro organismo requiere de nutrientes, pero la búsqueda descontrolada de comestibles, para llevárselos ansiosa y desesperadamente a la boca, advierte un desequilibrio que puede ser negado durante muchos años. Cuando se desea llenar el vacío con alimentos en vez de aceptarlo con cautela para buscar un nuevo modo de adaptarse a él, se obstaculiza la fecundidad que conllevaría permitirle. Se admite, por tanto, que la experiencia de cierta vacuidad es útil cuando a partir de ella se elige construir.

Otro de los excesos perjudiciales es el que se realiza con las bebidas alcohólicas. Nada se objeta aquí a la intención de festejo y celebración que acompaña al consumo de este tipo de bebidas, lo que se cuestiona es el adormecimiento del criterio que permitiría reconocer el límite en su consumo, la alteración que genera en el organismo y las múltiples consecuencias que deriva. Entre los problemas que conlleva está la alteración del sistema nervioso, digestivo e inmunológico, además de propiciar dependencia psicológica y adicción física. Por si esto fuera poco, las personas que eligen dañarse con sus excesos en la ingesta de bebidas alcohólicas también generan un efecto perjudicial en otras personas. Cuando el consumo es inadecuado se generan problemas económicos, estrés, inadecuación social, división familiar y desenfoques laborales. Además, un alto promedio de los accidentes viales está asociado al consumo de alcohol.

Tendríamos que apuntar, con toda claridad y agudeza, el cuestionamiento sobre a qué es a lo que se desea escapar cuando se elige "perderse" en las bebidas alcohólicas. No cabe suponer que se trata sólo de un travieso y curioso deseo de desconexión, pues tal intención maquilla un vacío que no se ha sabido manejar oportunamente.

En el mismo canal de afección por excesos está el uso del cigarro. Independientemente del tipo de tabaco que se consume, los fumadores provocan en su propio organismo una serie de afectaciones pulmonares. Otros perjuicios son el aumento de las posibilidades de desarrollar cáncer, 
repercusiones en el sistema respiratorio, bronquitis crónica, afectación del sistema cardiaco, posibilidad de infartos o deficiencias coronarias, problemas cerebro-vasculares y problemas circulatorios.

El cotidiano uso de drogas, entendidas como fármacos o principios activos de un medicamento que produce consecuencias en el sistema nervioso central, modifica el estado anímico y las reacciones ante los acontecimientos circundantes. Además de la evasión que suponen, las drogas también generan una desconexión que, a pesar de que para muchos está justificada en función de un supuesto despertar de la conciencia, no logra más que hacer que se pierdan de vista los signos de deterioro físico que requieren atención. Cabe decir que las drogas pueden ser muy diferentes en su fabricación o en sus características, e incluso pueden ser naturales. Las consecuencias y efectos de cada una no inhiben su calidad de potencial perjuicio no sólo en el organismo sino en la estructura general del individuo.

Por otro lado, el acto sexual, una de las experiencias potencialmente más profundas que un ser humano puede tener en su encuentro con otro, puede terminar siendo perjudicial cuando se le agrega el carácter de exceso. No sólo la frecuencia sino también la modalidad y la variedad de parejas sexuales pueden ser un indicativo de que el descontrol se ha apoderado de un individuo. Naturalmente, no se trata de proponer una vida casta o adoctrinar moralmente sobre lo permitido o lo prohibido en las experiencias sexuales, lo que se busca es proponer una intensificación de la vida sexual en función de su intimidad, de la cercanía que produce con la persona que se elige. El tipo de vivencia de vacío en una persona se relaciona con su vida sexual, puesto que el sexo, en un alto porcentaje, es necesidad de comunicación, tal como lo refirió el antropólogo mexicano Santiago Genovés.

Otro mexicano, Octavio Paz, afirmaba que en todo encuentro erótico hay un personaje invisible y siempre activo que es la imaginación. Por tanto, un factor fundamental en el encuentro sexual es el intercambio verbal sobre lo imaginado; sin embargo, cuando la comunicación no se ha logrado de forma adecuada en los terrenos afectivos se busca una compensación desenfrenada en otras áreas. Cuando tal compensación se vuelve una cotidianidad, la persona insatisfecha atenta 
contra su salud ocasionando que sus propios actos sexuales aumenten la dosis de perjuicio y daño. Además, la multiplicidad de parejas sexuales, o la vivencia sexual irresponsable, puede atraer embarazos no deseados, enfermedades venéreas y otro tipo de deterioros o percances.

La inadecuada vivencia del vacío empuja a cualquiera de los excesos corporales referidos. Si el cuerpo se atrofia o si su ejercicio biológico no es cumplido adecuadamente, las consecuencias psicológicas son devastadoras $\mathrm{y}$, a la vez, pueden generar nuevamente perjuicios corporales, continuando el ciclo.

Evidentemente, muchas de las enfermedades comienzan por un factor psicológico; esto alude al hilemorfismo que propuso Aristóteles (hyles: materia; morphé: forma), del cual se desprende que ambos constitutivos integran lo humano. La materia, entendida como cuerpo, y la forma, relacionada con el espíritu (que podría ser entendido como la psique), se vinculan en el funcionamiento del cuerpo. En ese sentido, si la somatización de aspectos psicológicos está referida a patrones inapropiados desde los cuales se estructura la realidad percibida, la valentía ante el vacío conduce a una modificación respecto de los modelos de vida establecidos culturalmente. Equipados con una adecuada tolerancia al vacío, dotados de actitudes precisas que permiten concebirlo como un interactuante inevitable en la vida humana, podrían reorganizarse las directrices psicológicas que conducen nuestros pensamientos. Al mejorar los pensamientos se sanarían también muchas enfermedades o se podrían volver más saludables los procesos corporales, evitando muchas de las atrofias y afecciones más comunes.

Al aludir a los excesos corporales como un obstáculo para el bienestar no se reproduce la idea de que los excesos son moralmente malos; en ese sentido, es radical la apreciación de Safransky en torno a lo innecesario de seguir abogando por actuar según lo moralmente bueno. Según sus palabras:

[...] la reflexión platónico-socrática sobre la vida buena está envuelta en dos sueños seductores. El sueño de una vida lejos de la agitación de la ciudad, y el de una vida distanciada de las maquinaciones del cuerpo. El primer sueño se refiere a la vida contemplativa, al 
biostheoretikos. El segundo sueño aspira a una soberanía libre del cuerpo, a la inmortalidad del alma. (Safranski, 2013, p. 38).

Asumir la vacuidad de la misma idea del bien es un punto de partida útil, para no supone que la invitación a evitar los excesos se centra en una intención moralista.

\section{Distractores}

Un proverbio irlandés afirma que quien vive sin disciplina muere sin honor. A pesar de que puede haber disciplinas que no conlleven un honor implícito, se entiende que la frase advierte la necesidad de prestar atención a los proyectos vitales que se hayan elaborado o a las cosas que cada individuo considere importantes para sí. Sin embargo, cuando la vida está orientada a la distracción, a la juerga, al desasosiego o a la desconexión continua, declinan las esperanzas de un acontecer apasionado, un ímpetu proactivo y un interés que impulse a la vida. Puede ser que la persona distraída aún no sea consciente de tal distracción pues, precisamente, está atraída a algo que no es de importancia fundamental para su vida. Para encontrar lo propio es necesaria una focalización concentrada. Stirner resume esta idea del modo siguiente:

Lo divino mira a Dios, lo humano mira al Hombre. Mi causa no es divina ni humana, no es ni lo verdadero, ni lo bueno, ni lo justo, ni lo libre, es lo mío; no es general, sino única, como yo soy único. Nada está, para mí, por encima de mí. (Stirner, 2014, p.59).

Si no se colinda con ese entusiasmo por la búsqueda en uno mismo, las distracciones serán cada vez mayores.

A pesar de que cada vez son más las voces que proponen olvidar el pasado y centrarse sólo en los proyectos venideros, bajo la suposición de que el pasado no importa, éste sigue teniendo relevantes conexiones y consecuencias en el presente. Las vivencias infantiles, las experiencias de antaño, los aprendizajes, testimonios, consejos y vivencias que fueron experimentadas, pueden estructurar sólidamente, con el debido sentido crítico, la fuerza del presente. Reconocer la influencia 
de la propia familia en la cosmovisión, el cariño recibido o la ausencia de tal, las formas y costumbres de establecer comunicación con los miembros de la familia, el rol que se adoptaba en la estructura familiar o el papel que se desempeñó en el sistema del propio grupo afectivo, son todos elementos dignos de tomar en cuenta. Si las distracciones presentes nos desconectan del pasado no hay manera de entender lo que se es.

No se aboga con esto a que permanezcamos en el pasado y a que descuidemos el momento actual por continuar una queja absurda sobre lo que nos haya sucedido antes; lo que se plantea es que la vida se entienda como una secuencia continua en donde todo tiene una conexión con las vivencias previas. Cuando las distracciones se limitan, pueden hacerse nexos más oportunos con lo que ahora mismo no es tangible. Al vivir cotidianamente sepultados por las cosas que nos aparecen como urgentes, dejamos de lado las esenciales. A pesar de que las urgencias cotidianas se multipliquen y siempre exista un pendiente que atender, es posible encontrar algún espacio silencioso, un hueco en el día que nos permita recordar que estamos vivos y que la existencia es algo más que cumplir una a una con todas las diligencias que hemos decidido cargar sobre nuestros hombros.

Si a esto le sumamos el exceso distractor, coincidente con las actitudes de aquellos que no sólo realizan sus pendientes sino que también eligen realizar los de los demás (volviéndose una especie de sirvientes afectivos de sus parejas, amigos, conocidos o familiares), la distracción se multiplica y el exceso sucede. Una actitud liberadora es no obstaculizar la responsabilidad que cada ser vivo debe ejercer sobre su propia vida. Cargar con lo que a otro corresponde es restarle un poco de vida a la existencia ajena, perdiendo de vista lo que se sustrae a la propia, precisamente, por la distracción que implica.

Además de distraerse con las urgencias de la vida cotidiana o hacer por otros lo que ellos podrían hacer por sí mismos, existe una tercera forma de distracción muy común, la cual consiste en dedicar varias horas al día y encauzar la propia energía a criticar la vida de los demás. Incluidas las difamaciones, los chismes o los chacoteos sobre lo que otros hacen, centrarse destructivamente en la conducta ajena es perder el foco del propio centro personal. Es comprensible que hablar de otro, 
de sus defectos, errores y problemas, genere cierta diversión, placer o sensación de superioridad; pero lo cierto es que el otro, al menos, no perdió ese valioso tiempo haciendo lo mismo o hablando de nosotros.

Cuando se condena inadecuadamente a otro, sin tener conocimiento claro de lo que se dice, se está invirtiendo tiempo (recurso no renovable) que se pierde. Además de perder horas valiosas en críticas innecesarias, se está generando una distracción de los asuntos y pendientes más fundamentales de la propia vida y, con ello, se está perdiendo más tiempo aún.

Mención aparte merecen los individuos que actualmente invierten tardes enteras en revisar lo que acontece en la vida de otros por medio de las redes sociales. Profundizan en lo que otros dicen en vez de preguntarse por lo que ellos mismos quieren decir o lo que significa para sí lo que viven en su propia vida. Cuando una persona habla inadecuadamente de otra y perjudica la fama ajena, pierde de vista que aquel con quien está conversando puede después traicionarla y hacer lo mismo con su propia fama. El Talmud sugiere la virtud de la discreción al referir que cada uno de nuestros amigos a quien contamos un secreto, o con quienes elaboramos improperios hacia otros, tienen también otros amigos que, a la vez, tienen otros más. Los secretos o las críticas se esparcen por doquier, el viento es muy comunicativo.

Otra distracción recurrente es el juego. A pesar de que en la actividad lúdica puede encontrarse sana diversión o una desconexión necesaria relacionada con el descanso, también hay juegos que se perpetúan cuando, precisamente, se han vuelto excesivos. Vivir la vida continuamente para la diversión, festejando sin motivos, riendo sin parangón, permaneciendo optimistas y ajenos a lo que nos muestra nuestro alrededor, no es sinónimo de adultez. No se alude aquí al juego en el que uno se permite experimentar, conocer o investigar, aquel que nos empuja cuando la curiosidad se vuelve constructiva, sino del que es un continuo distractor, el que tiene por única intención, o al menos la principal, no hacer frente a los problemas, recluirse en coqueteos superficiales con actividades de poco sentido.

Dejar que el tiempo transcurra sin utilidad es como sentarse a observar el escurrir de la propia vida. Muchos de los juegos excesivos (que terminan por ser perjudiciales) están asociados con 
apuestas o contiendas de azar, aquellos en los que se espera la buena fortuna, un buen día o una bendición sobrenatural que nos vuelva ganadores ante la evidencia cotidiana del día a día que nos afirma que no lo somos. Es infantil esperar ser otra persona en un instante, convertirse de perdedor a ganador sólo por tener un poco de suerte en el casino o acertar en el manejo de las cartas. Aunque en alguno de esos juegos se obtenga dinero, no se obtiene con ello el valor de aprovechar el tiempo de formas productivas.

Otro distractor común es mantener ciertas poses. Cuando se busca dar una imagen que uno no es se está usando un disfraz, se acentúa una etiqueta, se gesticula, se habla, se viste o se camina como quien se anhela ser, aunque no se sea. Esto es un distractor que produce una leve tranquilidad bajo la sugestión de que se está logrando el cometido. La pose es sólo un maquillaje, es la apariencia desde la superficie. No suele pasar mucho tiempo para que aquellos que interactúan con alguien que vive en una pose terminen por descubrirla, sobre todo cuando se han generado expectativas sobre lo que es el otro. La tranquilidad obtenida por la aceptación momentánea que la pose otorga, deviene en frustración cuando el rechazo es evidente.

Otra distracción es la que genera la ignorancia. Es más fácil engañar a una persona que sabe poco, debido a que está acostumbrada a engañarse a sí misma. El que poco sabe, poco duda; por el contrario, de los grandes conocimientos se engendran las grandes dudas, solía considerar Aristóteles. Una persona que se niega la posibilidad de dudar está, innegablemente, distraída. Son muchos los pretendidos intelectuales que han dejado de dudar de sus saberes, así como son cotidianos los acaudalados que no dejan espacio para la reflexión en sus agendas ocupadas.

No es el exceso o la apariencia lo que propicia el bienestar. Pensar que se es docto por tener libros en la biblioteca personal (o en las carpetas digitales de una máquina) es como asumir que tener fotografías de distintas mujeres nos da un romance con ellas. Tampoco nos hace místicos memorizar el evangelio o conocer el nombre de los curas de la parroquia, aun cuando de buena fe omitamos el recuerdo de sus evidentes pecados. No se es mejor profesor por tener anotadas en planeaciones excelsas lo que a cada minuto se dirá en la clase ni por asistir a las pérfidas reuniones académicas que convocan algunos coordinadores que encuentran en el control la única evidencia de su pretendida y 
nula autoridad. De ningún modo se está mejor alimentado por saturarse el estómago al grado de no poder ponerse de pie, ni se es el alma de la fiesta por trastabillar en la pista de baile debido a los efectos del alcohol. No se es un comunista sólo por leer a Marx, ni se obtiene oficio de psicoanalista sólo por endiosar a Freud.

En todos los casos, pensar que el exceso conlleva un aseguramiento de lo anhelado es permanecer en la inocencia. La templanza, entendida como una justa medida de lo que a cada uno corresponde para lograr lo que desea, es obstaculizada cuando el exceso se vuelve una costumbre. Realizar una adecuada comprensión del vacío consistirá, en este caso, en permitirse encontrar el motivo intrínseco, escondido o entre líneas, que motiva al exceso que nos ocupa y agota.

\section{Excesos de adhesión social}

La confluencia no sólo acontece en las relaciones interpersonales sino también en las de un individuo hacia un grupo social determinado, sea entidad colectiva concreta o abstracta. Una conglomeración de individuos reunidos por un motivo religioso, científico, cultural, tecnológico, laboral, familiar, educativo, político, deportivo o delictivo, representa una colectividad. Cuando la unión de un individuo con el grupo de referencia al cual desea pertenecer es tal que termina por diluir a la persona en él, nos referimos a un exceso de adhesión social.

Una de las intenciones individuales de la vida en sociedad es lograr integrarse a un grupo, ser reconocido, admirado o apreciado por lo que se es capaz de ofrecer a la colectividad. No obstante, cuando la intención por sobresalir, ser visto o ser querido, termina por corromper al individuo, no hay manera de sostener el provecho inicialmente buscado. En los diversos grupos sociales existe una tendencia natural a reglamentar los comportamientos y son éstos, precisamente, los que marcan una distinción con el resto de los grupos y los individuos que los conforman. Una máxima conductual en un grupo religioso puede ser mal vista en un grupo científico y viceversa; del mismo modo, una exhortación en el terreno político podría ser distinta a una ejercida en el ámbito deportivo.

Un claro ejemplo de lo anterior, en el ámbito de los grupos religiosos, es cuando una persona se prohíbe a sí misma, debido a la coacción externa de las autoridades, dudar de la funcionalidad de 
lo que se le ordena a través de la interpretación de los libros sagrados o de la doctrina a la cual se adhiere. De tal modo, cuando disminuye la capacidad crítica hacia las creencias, aumenta proporcionalmente el exceso de la adhesión al grupo. Naturalmente, la renuncia al propio sentido crítico será reforzada con la aprobación del grupo. El vacío es llenado al sentir que se ha logrado ser parte de una comunidad. Tarde o temprano, si el afectado tiene suerte, logrará vivir algún desasosiego que le permita despertar, o bien, si su sueño continúa, seguirá envuelto en la retórica religiosa.

Por otro lado, en ciertos grupos de orden científico, la regla implícita consiste en impedirse dudar de la racionalidad o de la rigurosidad. Embelesados con los avances del conocimiento, algunos científicos se alejan de la conciencia de que todo saber está mediado por los filtros epistémicos siempre limitados que humanamente nos conciernen en los procesos de cognición. Pertenecer a un grupo científico y no tener la habilidad de regresar a la cotidianidad, al silencio o al encuentro con los ciudadanos que no acceden a las distinciones académicas, es una forma de desconexión. Anhelar conocimientos y ser valiente en su búsqueda es una virtud, pero devorar libros ansiosamente, intentando ocultar en tal interés las pulsaciones derivadas del miedo a encontrarse sin respuestas, es un indicativo distinto. El uso del poder vivido en la academia, las implicaciones políticas y mediáticas que en ocasiones supone, así como el aburrido énfasis en el anhelado control de la realidad, termina por eludir los espacios vacuos que podrían ser altamente provechosos para las personas dedicadas a la investigación.

No se afirma con esto que sea oportuno separarse de los grupos académicos y científicos, lo que se admite es que permanecer en tal rol, mantener la misma actitud en todos los órdenes de la vida, nublarse la vista por desear verlo todo con un mismo matiz y terminar compitiendo con otros por ver quién tiene la razón verdadera, es algo ocioso. Situaciones similares acontecen cuando una persona se adhiere a un grupo cultural o tecnológico y sigue ciegamente las reglamentaciones sobre cómo se debe crear el arte o la manera unívoca de elaborar una propuesta tecnológica.

Del mismo modo, son reiterados los casos en que los individuos que viven divididos por vivir más para su trabajo que para su propia persona terminan por convencerse de que ése es su camino 
al éxito. La idea de que el éxito se logra a través de entregar la propia vida en el proceso ha sido repetida y promovida sin cesar. Ser un empleado es aceptable en cierto modo, pero dejar de ser persona para convertirse en una máquina que realiza oficios esuna mediación deshumanizante. Russell señaló que:

[...] la tiranía de las grandes organizaciones mecanizadas, gobernadas desde arriba por hombres que conocen y se cuidan muy poco de las vidas de quienes dirigen, está matando la individualidad y la libertad mental y forzando a los hombres, cada vez más, a conformarse con un prototipo uniforme. (2013, p.31).

A pesar de ello, son muchos los individuos que están dispuestos a continuar así, pues esa forma de automatización les permite desconectarse de sí mismos y, por ende, el vacío que experimentarían (al verse o centrarse en lo que son) es evadido. El exceso de cohesión social es una salvaguarda desde la cual se logra eludir la conciencia de que uno mismo no es lo que cree.

De tal modo, cuando a alguien se le afirma que es el empleado del mes, el brillante trabajador de la empresa tal o cual, el tenaz asistente del director e, incluso, el líder de la firma nacional o internacional que se guste, se le está otorgando una identidad que tranquiliza momentáneamente la incertidumbre derivada de desconocerse; esto durará, al menos, el tiempo que transcurra hasta el siguiente recorte de personal, la fricción emocional con algún alto directivo envidioso o, simplemente, la causalidad laboral. Así, los pretendidos indispensables terminan desechados, suplidos, maniatados y excluidos. La crisis sobreviene, las dudas emergen: ¿Qué espécimen raro represento si he sido expulsado de la institución a la que doné los mejores años de mi vida? La ansiedad puede amainarse pronto y siempre habrá una nueva organización empresarial que abra sus brazos controladores para apaciguar la voluntad del individuo, un corporativo que muestre sus dientudas fauces para devorar al atónito desempleado que conciliará un nuevo sueño.

No podemos creer la ficción de que lo que somos está reflejado en lo que representamos para una institución cuya naturaleza implícita es utilizarnos para cumplir funciones o lograr indicadores que no constituyen, de ningún modo, parte esencial de nuestra existencia. Octavio Paz considera que 
no solo son incorrectas nuestras ideas respecto a lo que somos, sino que incluso no hay manera de encontrar una identidad definitiva. En palabras del mexicano: "Ninguna realidad es mía, ninguna me (nos) pertenece, todos habitamos en otra parte, más allá de donde estamos, todos somos una realidad distinta a la palabra yo o a la palabra nosotros" (Paz, 2014, p.44).

Otro grupo con implicaciones de mayor intimidad es el núcleo familiar al cual pertenecemos. No importa que nos hayamos distanciado físicamente o que nuestra residencia se encuentre a kilómetros de distancia, la influencia familiar persiste si se permanece anclado a los lineamientos afectivos que aderezaron nuestro crecimiento. Las reglas del padre, de la madre, de los hermanos, de los tíos y primos, todas son una especie de indicación sobre lo que debe hacerse para ser alguien. A muchos se les habrá juzgado por no ser lo suficientemente atractivos, inteligentes, atléticos, obedientes, activos, creyentes, serviciales, simpáticos, artísticos, risueños, simpáticos o sumisos. Siempre existe un algo que faltó, siempre una ausencia, un constante motivo para no ser lo que se esperaba. Aquellos que creen que han sido exactamente lo que se esperaba de ellos no han despertado a la noción de que eso les impidió lograr lo que habrían podido ser si no hubiesen estado sometidos a tales lineamientos.

Como es de esperar, no hay familia sin reglas, aun cuando éstas no sean siempre escritas, colgadas en una pared de la cocina, o recordadas en la parte trasera de la puerta del propio cuarto. Las reglas están implícitas en lo que se dice y en lo que se calla, en lo que se advierte y en lo que se disimula, detrás de las aprobaciones, los aplausos, las encomiendas o las exhortaciones y castigos. La adhesión excesiva al grupo familiar se evidencia cuando una persona se apropia de una identidad grupal que no es necesariamente coincidente con la esencia particular. En todas las familias existen los desadaptados que permiten que el resto sea, curiosamente, afecto a sentirse bien por su adaptación. La complicidad no siempre es consciente pero sí consecuente del hecho de estar en un grupo de cohesión. Es sano lograr una separación que no implique renuncia radical, sino la distancia oportuna desde la cual es posible distinguir entre lo que se es y el rol que se desempeñó, entre lo que es un constitutivo de la propia identidad y lo que son colguijes adaptativos que tuvieron que utilizarse en el camino. 
Similarmente, la institución educativa a la que pertenecimos nos inculcó un modo de entender la vida social. Según Pierre Bourdieu, sociólogo francés, la escuela o colegio termina reproduciendo en nosotros los parámetros y modalidades de lo que se entiende por un buen ciudadano. Más allá de la evidente violencia simbólica que esto supone, se obstruye la libertad de considerar otras posibilidades. El niño que sostiene un libro en sus manos con los brazos extendidos, el que se encuentra en el rincón y el que hace planas al final de la clase, son todos representativos de una coacción paraadaptarse a un sistema establecido. Si estas imágenes parecen caducas, aunque creo lo contrario, se pueden establecer otras evidencias más contemporáneas.

Obligar a que un individuo utilice ciertos métodos, adopte tales o cuales creencias, se adhiera a un sistema de aprendizajes en el que está forzado a formar parte de un grupo integrado por personas con capacidades distintas (mayores o menores) y sea inducido a acoplarse a un ritmo grupal que delimita su propio desempeño en pro de una tolerancia no elegida, son ejemplo de sometimiento implícito socialmente aceptado; además, el estudiante está sujeto a la eventualidad de que quien juega el rol de enseñante, profesor o facilitador, realmente cuente con las habilidades para realizar eficientemente su labor. ¿Hemos creído que se puede llamar facilitador al individuo que, envuelto en la ola de variedad que le representa un grupo con varias decenas de adolescentes, sólo es capaz de mantener la disciplina por unos minutos? ¿Realmente suponemos que los planes de estudio de nuestros estudiantes los equipan para un futuro desconocido que ofrecerá (seguramente) condiciones y herramientas distintas a las que hoy contamos? ¿Qué pensamos que estamos haciendo cuando decimos que preparamos a las próximas generaciones para un futuro que desconocemos? Ellos, sin otra alternativa, adoptan el rol sumiso al que son encajonados, se les ofrece un plan de vida prefabricado, se les forza a formar parte de las instituciones educativas que les plantean un modelo de éxito, de sociedad y de estructuración socioeconómica. Buscamos que la educación unifique a la sociedad cuando esencialmente genera división, la cual se fomenta con la exclusión de los que no cuentan con recursos para el pago de la colegiatura en las instituciones privadas y con la precariedad común (salvo honrosas excepciones) de las alternativas públicas. 
A pesar de que puedan no existir desfases significativos entre los aprovechamientos académicos de los estudiantes de instituciones públicas y privadas, el mensaje que ya ha quedado implícito es el de la división y clasificación socioeconómica, a pesar de que en las instituciones se busque la tan fantasiosa igualdad social o la similitud de oportunidades. No es deseable, por tanto, que los ideales de una institución deban ser forzosamente compartidos por los individuos que egresan de las mismas.

Otra alienación significativa es la que acontece en el terreno político. Es lamentable que los acuerdos sobre las reformas políticas sean negociados a partir de las filiaciones grupales y no por derivación de las reflexiones, criterios o razones. Cuando los políticos eligen a sus dirigentes a partir de los colores de un partido o de los intereses de su propia carrera representativa, se está dejando de hacer política auténtica y el sector de la representación social se vuelve un cultivo de grillos que olvida el progreso de la mayor parte de la sociedad. Se ha tergiversado la función del político y ahora es confundido con el individuo beneficiado por propaganda sin contenido, elevado a la categoría de todopoderoso a través de la intervención mediática que convence a multitudes huecas. Los acuerdos políticos éticos e inteligentes cuya intención es la construcción de una nueva sociedad han sido diluidos en función de ejercicios de poder centrados en compromisos, acuerdos o alianzas estratégicas. Cuando un ciudadano pierde su capacidad reflexiva y se vuelve un seguidor ciego de personajes más que de propuestas, de colores partidistas más que de filosofías políticas, se ha perdido en el camino y es más fácil de manipular. Actualmente, la tiranía se vende con apariencia de democracia, la autoridad se obtiene a través de la popularidad y el control se impone a los oídos ingenuos.

Por otro lado, no podemos ser tan absurdos como para proclamarnos apolíticos, sino todo lo contrario: asumirnos políticos en cuanto que somos ciudadanos que conforman una comunidad. Aún así, el grupo social al que pertenecemos, nuestra nacionalidad como tal, es también una representación ficticia de la humanidad que contenemos. Ningún humano carga con su pasaporte para poder nacer ni contiene un color partidista en su sangre (por más que el rojo de la misma se asocie al comunismo). Las banderas son adoptadas, son anclajes, son contenedores de una identidad 
difusa. Cada humano, además de reconocerse estructurado socialmente por una función política, una nacionalidad y una identidad cultural, ha de asumirse alejado esencialmente de todo ello, pues siempre hay un vacío que le corresponde tras la desconexión con cada una de tales ficciones. En caso de que un individuo tenga la valentía de trascender esos símbolos, y el útero de la nada le permita el parto de un sentido vital alternativo, su propia vida política y su ciudadanía serán aún más fecundas y productivas.

Aunque parezca de inferior dimensión, la esfera de lo deportivo atrae también a identidades confusas que se agolpan tras los colores de algún equipo o asociación y encuentran en ellos lo que creen ser su esencia más íntima. Si bien la filiación a un equipo deportivo, el uso de las instalaciones de un club o la asistencia a una competición atlética (cualquiera que sea la práctica deportiva colectiva a la que nos refiramos) puede ser divertida, un pasatiempo o una intención lúdica, también llega a convertirse en un obstáculo para la vivencia sana del vacío en caso de que se torne excesiva y la persona viva en confluencia, se adhiera o fusione a un logotipo, escudo o representación. Esperar a que llegue el fin de semana con la única intención de sentarse en el acolchonado y afelpado sillón hogareño, devorar toda la programación deportiva, asistir a los estadios o casi adorar a los jugadores emblemáticos, es un distractor. Llorar cuando el equipo pierde o sufrir cuando no logra ganar, enfrentar a otros por sus preferencias distintas (casi militantemente) u olvidar los propios quehaceres en función de la asiduidad deportiva, es contrario al interés de focalizarse en uno mismo y los demás.

Sin embargo, la filiación deportiva es menos perjudicial, aun siendo excesiva, que encontrar una identidad en grupos delictivos o, peor aún, terroristas. La pertenencia a grupos violentos puede ser un factor de evidente desconexión personal. Adoptar los roles, las formas, las reglas, los modos de vida, la ideología y las conductas que reflejan los instructores jerárquicos de los grupos de este tipo propicia que, paulatinamente, la persona genere la ficción de que se encuentra bien, que es alguien exitoso. En algunos casos, la violencia es una respuesta personal a la imposibilidad de inclusión en otros grupos con mejores condiciones. Rollo May afirmó que "la violencia es el último sustituto destructivo que aparece para llenar el vacío donde no hay ninguna relación" (May, 2011, p.30). 
En forma muy general existen cuatro tipos de pertenencia a grupos: a) cuando sucede sin que la persona se pierda a sí misma en su inclusión o se diluya por ser parte de la colectividad, sabiendo que esencialmente no es parte del grupo pero que lo requiere para asociarse en función de su inevitable configuración de estar abierto al mundo; b) cuando la pertenencia sucede (aún en el colectivo de los no incluidos) a partir de una minimización personal o de un forzamiento que conlleva una despersonalización; c) cuando la inclusión generó un resultado perjudicial que atrae un interés por vengarse de la sociedad, responder violentamente a los miembros de otros grupos establecidos o a toda representatividad que atente contra el grupo beligerante al que se pertenece; d) cuando no ha sido posible la inclusión tangible y se forma parte de la abstracta colectividad de los que se autodestruyen por no concebirse parte de algo.

En el último de los modos de pertenencia pueden estar incluidas las eventuales conductas auto-lesivas, usualmente propiciadas por la nula inclusión a un grupo de referencia o por la pertenencia forzada o insana que, debido a una connotación peyorativa del vacío, no ha permitido cauces saludables, ya sea por sabotajes o por contradicciones inducidas. Se observa, entonces, que la vivencia del vacío y la gestación de un sentido personal no son solamente un artificio poético que intenta ser medianamente filosófico; todo lo contrario: la vivencia del vacío es una necesidad en un mundo azotado por vaivenes distractores que generan repercusiones de alta calamidad social, nacional e internacional. La sana vivencia del vacío, que se advierte en la primera alternativa de pertenencia referida, pretende encauzar la energía de los individuos hacia la procuración de ambientes más naturales, oportunos y propicios para el desarrollo de la conciencia. Por el contrario, la pertenencia enajenante a instituciones y grupos o la exclusión penosa de los mismos, por voluntad propia o por incumplimiento de sus estándares, acarrea dificultades de mayor envergadura.

No puede objetarse que la violencia es una forma de empoderamiento. Tal como refiere Thomas Carlyle, pensador escocés, es un error esencial considerar la violencia como una fuerza. Por el contrario, la violencia es un ejercicio derivado de la falta de fuerza o su inadecuado encauzamiento; en su desproporción, la violencia otorga una compensación que es ilusoriamente auto-afirmativa, pues no coincide con las estructuras esenciales de las que se deriva la identidad más íntima de cada 
individuo. La violencia propicia destrucción irracional, desmedida y desenfocada, reproduciéndose a sí misma al generar reacciones similares en los individuos violentados. La violencia termina por aniquilar a quien le permitió emerger.

En ese sentido, no sólo la violencia de los grupos delictivos sino incluso la derivada de las guerras no resulta favorecedora para las naciones implicadas. Luther King afirmó que la violencia crea más problemas sociales que los que resuelve. En ese tenor, un vacío inadecuadamente canalizado nos produce un malestar mayor del que originalmente podría producir.

\section{Exclusividad afectiva hacia un objeto}

Una última forma de confluencia es la referida a objetos o bienes tangibles, incluido el dinero. En los casos en que el apego es de dos personas entre sí, el despertar de uno puede orillar a una conciencia de la confluencia en el otro; distintamente, cuando la confluencia implica una exclusividad afectiva hacia los objetos, implicando una consecuente adhesión excesiva, no reporta una alternativa de confrontación si el individuo apegado no genera conciencia de su situación de forma autónoma. En ese sentido, el apego aparenta ser un antídoto ante el vacío, pero se convierte, más temprano que tarde, en una alternativa insuficiente.

No se afirma que el dinero sea algo poco importante; vivimos en una estructura sociopolítica que legitima el poder adquisitivo del dinero. A partir de él se logra obtener privilegios, confort y un alto número de placeres. Groucho Marx, cómico estadounidense, solía decir que las cosas más importantes que el dinero suelen costar más. Obviamente, en esa alusión refería que la mayoría de las cosas del mundo contemporáneo están relacionadas con el baluarte económico. Por su parte, Jeanne Bourgeois, actriz francesa, apuntaló que el dinero no da la felicidad, pero aplaca los nervios. De tal modo, no hay forma de negar los evidentes beneficios que otorga una posición económica holgada. Sin embargo, centrar la vida, los intereses y el bienestar únicamente en el dinero es una forma de huir del vacío, es negarlo inútilmente.

El aspecto económico no siempre supone paz y situaciones provechosas; no olvidemos que muchas familias, grupos, naciones y civilizaciones enteras se han dividido, enfrentado y separado 
debido al interés desmedido por el dinero. En su justa medida, el dinero es un recurso (un medio y no un fin) que debería ser orientado a la consecución de utilidades, al cultivo de bienestar. Es por eso que Krishnamurti, místico indio, aludió que morir en la riqueza significa haber vivido en vano, en el sentido de que se desaprovecharon los recursos si no fueron utilizados en crear el bienestar de otros. El progreso de las naciones está muy relacionado con el uso que se hace en ellas del dinero. El bienestar de un país está vinculado al aprovechamiento de los recursos monetarios con los que cuenta, el cauce favorable de los impuestos o la obtención de alternativas de poderío económico. Cuando el dinero es buscado más como un factor de prestigio social, de supremacía y distinción, que como un recurso para proveer de alternativas para el bienestar o la productividad de la mayor cantidad de personas, será contrario al beneficio público y no aportará un rendimiento social.

Jenofonte, filósofo griego, invitaba a que nadie dijera que el dinero era un bien si no se sabía hacer un buen uso de él. No son pocas las personas que han atraído a su vida mayores daños que beneficios a partir de su acaudalada situación; tampoco son escasas las tragedias en las que muchos se han envuelto por proteger su prosperidad, ni son raros los casos en que el interés desmedido por propiciar mayores riquezas origina ansiedades que desencadenan enfermedades cardiacas; por ello, es posible admitir que Jenofonte tenía cierta razón y que la focalización excesiva en el dinero, o al menos la manera en que es concebido, puede resultar problemática.

El dinero, aquel que sobra cuando se han satisfecho las necesidades básicas, puede ser un distractor del vacío personal. La búsqueda por el confort que el dinero otorga es también una ocupación cotidiana que puede alejar de la tan necesitada noción de carencia. Del mismo modo, la exclusividad afectiva puede estar centrada en bienes, productos, artefactos o tecnologías que se obtienen a partir del dinero. La compulsión hacia la obtención de ciertos artículos, o el afán coleccionista de muchos individuos, se arraiga en la necesidad de llenar espacios o huecos que no son necesariamente externos. La obsesión por la posesión está relacionada con la desadaptación hacia el propio vacío; el deseo de control tangible a partir de la acumulación de cosas o productos refleja una apetencia por ocultar, detrás de los artículos adquiridos, la tristeza que no se quiere observar. 
Aquellas personas a las que les cuesta el desprendimiento, el fluir libre de las cosas o soltar sus posesiones, también les resulta proporcionalmente difícil evitar la acumulación. La necesidad de saturar o de poseer en demasía ciertos objetos, cosas y artículos, está muy relacionada con la intención de aprisionar ideas, conceptos o representaciones añejas.

Los insultos, los sentimientos desagradables, el coraje, la envidia, el temor o la discordia que se acumulan por muchos años están dentro de la persona, casi fosilizándose, por no saber cómo deshacerse de ellos. Creemos que toda esa basura está llenando nuestro vacío pero, muy por el contrario, lo está perpetuando. Deshacerse de cosas anquilosadas, o realizar una limpieza general en la propia casa, es una liberación simbólica del contenedor mental.

Es probable que nuestro recipiente psíquico se encuentre saturado, pero se mantendrá con espacios vacíos mientras más se le quiera llenar con posesiones. De tal modo, tratándose del vacío, en la medida en que más se le quiere llenar más se le agranda. Por el contrario, si no se niega el vacío, ni se le quiere llenar desesperadamente, cederá y facilitará la llegada de otras condiciones. El vacío no se llena, se le permite vaciarse de sí mismo; una vez que se fomenta un libre cauce a las cosas que ocultan al vacío, éste se vuelve fecundo.

Soltar a otro, o desprendernos de las ideas que nos esclavizan a una idea de otro, es un ejercicio complejo que involucra dejar ir algo que nos ha definido por varios años. Si soltamos las propias ideas sobre lo que somos, el tan famoso autoconcepto, seremos alguien diferente a quien tendremos que conocer o reconocer y a quien tampoco podremos encasillar en una nueva ficción. Si bien somos indefinibles, nuestra indefinición no es tan perjudicial como nuestra necesidad de definirnos; tal imprudencia genera concepciones claramente erróneas, incompletas, tendenciosas y desfavorables.

No se trata de no dejarnos influir por ninguna idea de lo que somos, de desechar los recuerdos y de tirar inmediatamente todas las cosas que hemos adquirido en la vida. Se trata de no encasillar lo que somos en una serie de objetos que pueden estar sobre una mesa, ni a una conglomeración de ideas cuya variabilidad es sostenida. Podemos guardar algunas de nuestras etiquetas personales en 
un cajón del escritorio en el que redactamos la novela de nuestra vida, sólo así lograremos limitar la distracción que nos generan.

No tenemos que esperar a que mueran las personas que consideramos un obstáculo ni a que terminen las situaciones problemáticas por sí mismas. Si las cosas distractoras de nuestra vida no nos permiten encontrar el teclado desde el cual creamos la propia historia, es tiempo de una limpieza a fondo. Si en tal misión nos desconcentra el miedo de no tener referentes para vivir, será oportuno considerar que el vacío posibilita alternativas incontables, todas dignas de ser consideradas.

\section{Conclusión}

Si la apología del vacío permite que hombres y mujeres logren hacer de la vacuidad una parte de su vida, se obtendrán los siguientes beneficios concretos: 1) disminuir la necesidad de redundar en excesos corporales, todos ellos dañinos para la salud. Al no estar sometida a la necesidad de llenar el vacío, la persona se librará de saturaciones sensoriales que la alejan de su paz; 2) reducir el efecto de los distractores en la cotidianidad de cada individuo, de tal modo que sea mejorable la focalización decidida hacia las cosas, proyectos, personas o intereses que sean mayormente atractivos y potencialmente benéficos; 3 ) encontrar el centro propio y apreciar una intimidad más resguardada, lo cual acortará el anhelo de adhesiones sociales excesivas o sometimientos a distintos grupos que profieran dogmas, reglas o artificios ideológicos; 4) aminorar las exclusividades materiales que provocan centrar la atención energía y pasión en cosas incapaces de ofrecer una mutualidad afectiva compensatoria.

\section{Referencias:}

May, R. (2011). Amor y voluntad. Contra la violencia y la apatía en la sociedad actual. Barcelona: Gedisa.

Paz, O. (2014). El mono gramático. Barcelona: Galaxia Gutenberg.

Russell, B. (2013). Antología. Ciudad de México: Siglo XXI.

Safranski, R. (2013). El mal o el drama de la libertad. Barcelona: Tusquets.

Stirner, M. (2014). El único y su propiedad. Ciudad de México: Sexto Piso. 